\title{
Samsun ve çevresinde evcil hayvanlarda görülen zehirlenme vakalarının sistematik toksikolojik analiz prensipleri çerçevesinde değerlendirilmesi
}

\author{
Orhan TOKUR ${ }^{1, a}$, Özge MARANGOZ ${ }^{1, b}$, Zeyno NUHOĞLU ${ }^{1, c}$, Saima MUSHTAQ ${ }^{1, d}$, Aylin PEHLIVAN ${ }^{1, e}$, \\ Ŏguzhan YAVUZ ${ }^{1, f^{*}}$
}

${ }^{1}$ Ondokuz Mayls Üniversitesi, Veteriner Fakültesi, Farmakoloji ve Toksikoloji Ana Bilim Dall, Samsun, Türkiye

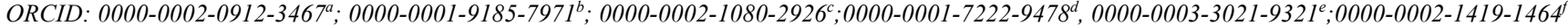

MAKALE BILGISİ /
ARTICLE
INFORMATION:
Geliş / Received:
05 Şubat 2021
05 Febuary 2021
Kabul / Accepted:
10 Mart 2021
10 March 2021
Anahtar Sözcükler:
Sistematik toksikolojik
analiz
Veteriner
Zehirlenme

Keywords:

Systematic toxicological analysis

Veterinary

Poisoning
ÖZET:

Hayvanlarda zehirlenmeye neden olan ilaçlar, pestisitler, mikotoksinler gibi fizikokimyasal olarak farklı çok sayıda madde bulunmaktadır. Bu nedenle, zehirlenme şüpheli örneklerin toksikolojik analizleri zorlu ve karmaşı süreçtir. Zehirli maddelerin çeşitli örneklerde belirli bir protokol içerisinde taranması işlemi olan sistematik toksikolojik analiz (STA) ile bu karmaşa giderilmekte, doğru ve hızlı teşhis sağlanabilmektedir. STA protokolü, numunenin alınması, örnek hazırlama, ön ve ana tarama testleri, miktar tayini, verilerin değerlendirilmesi ve sonuçların raporlanması basamaklarını kapsamaktadır. Toksikoloji laboratuvarının hizmet verdiği bölgelerde sıklıkla meydana gelen zehirlenmeleri bilmesi ise STA protokolünü bir adım ileri taşımakta ve doğru teşhis oranını artırmaktadır. Bu çalışmada, Samsun ve çevresinde hayvanlarda meydana gelen zehirlenme vakalarının ve sıklıkla zehirlenmeye neden olan maddelerin belirlenmesi, böylece toksikoloji laboratuvarında kullanılan STA protokolünün geliştirilmesi amaçlandı. Bu amaçla Samsun ilinde görev yapan 40 veteriner hekime (38 erkek, 2 kadın), sıklıkla karşılaştıkları zehirlenme vakaları ile ilgili anket uygulaması gerçekleştirildi. Anket sonucunda Samsun ilinde hayvanlarda son beş yılda en fazla görülen zehirlenme nedenlerinin sırasıyla pestisitler, bitkisel zehirler ve ilaçlar olduğu belirlendi. Zehirlenme şüpheli vaka sayısı hayvan türlerine göre köpek (131), sığır (109), koyun (76), kedi (22), kanatlı hayvanlar (22) ve at (2) olarak tespit edildi. Katılımciların \% 65 'inin $(n=26)$ zehirlenme şüphesi ile son beş yıl içerisinde laboratuvara hiç numune göndermediği tespit edildi. Elde edilen veriler ve güncel literatürlerin incelenmesi neticesinde, STA'nın zehirlenme vakalarının doğru teşhis protokollerinin oluşturulmasında hızlı, güvenli ve etkili bir süreç olduğu sonucuna varıldı.

\section{Evaluation of poisoning cases in domestic animals in the Samsun province within the frame of systematic toxicological analysis principles}

ABSTRACT:

\begin{abstract}
There are several physicochemically distinct substances that cause poisoning in animals, such as drugs, pesticides, mycotoxins. Therefore, toxicological analysis of suspected poisoning samples is a difficult and complex process. Systematic Toxicological Analysis (STA), which is an operation protocol used to scan toxic substances in different samples, eliminates this confusion and provides a precise and rapid diagnosis. The STA protocol covers the steps of sampling, sample preparation, screening tests, quantitation, data evaluation and reporting of the results. The fact that the toxicology laboratory is aware of the common causes of poisonings in the regions it serves, adds one step further to the STA protocol and increases the rate of correct diagnosis. The aim of this study was to identify common animal poisonings and common toxic substances in Samsun, thereby improving the STA protocol used in the toxicology laboratory. For this purpose, a questionnaire regarding the frequently encountered poisoning cases was conducted to 40 veterinarians ( 38 males, 2 females) working in Samsun province. As a result of the survey, it was found that the most common causes of poisonings in animals in the last five years were pesticides, herbal poisons and drugs, respectively. The numbers of suspected cases of poisoning by animal species were determined as dogs (131), cattle (109), sheep (76), cats (22), poultry (22) and horses (2). It was determined that $65 \%$ of the participants $(n=26)$ did not send any poisoning suspected samples to the laboratory. Based on the obtained results and current literature data, it was concluded that STA is a fast, accurate and effective process for establishing correct diagnostic protocols for poisoning cases.
\end{abstract}

How to cite this article: Tokur O, Marangoz Ö, Nuhoğlu Z, Mushraq S, Pehlivan A, Yavuz O: Samsun ve çevresinde evcil hayvanlarda görülen zehirlenme vakalarının sistematik toksikolojik analiz prensipleri çerçevesinde değerlendirilmesi. Veteriner Hekimler Dernegi Dergisi, 92(2): 111-121, 2021, DOI: 10.33188/ /vetheder. 874904 


\section{Giriş}

Organizmaya oral, dermal, solunum gibi çeşitli yollarla girerek canlının hayati fonksiyonlarına zarar veren ya da ölümüne yol açan maddeler zehir olarak tanımlanır. Yılan, akrep zehirleri gibi hayvansal ve glikozidler, alkaloidler gibi bitkisel zehirlerin yanı sıra bazı mineral maddeler ve pestisitler gibi çok sayıda bileşik zehirlenmeye neden olabilmektedir (24). Veteriner hekimlik alanında kedi ve köpeklerde sıklıkla olmak üzere inek, koyun, keçi gibi çiftlik hayvanlarında, kuşlarda, yaban hayvanlarında ve balıklarda zehirlenme vakalarına rastlanmaktadır. Bu vakaların çok azı doğru şekilde teşhis edilebilmekte ve birçoğu ölümle sonuçlanmaktadır $(8,12,13,21,22)$. Zehirlenme vakalarının hızlı ve doğru teşhisi, bir yandan tedaviyi yönlendirerek hayat kurtarırken, diğer yandan adli vakalarda ve ölüm sonrası incelemelerde ölüm sebebine ilişkin kesin tanı konulabilmesine yardımcı olmaktadır (37).

Zehirlenme şüphesi ile laboratuvara gönderilen maddelerin analizinde birçok zorlukla karşılaşılmaktadır. Her şeyden önce dünya üzerinde birbirinden farklı özellikte binlerce zehirli kimyasal madde bulunmakta, bu sayıya ilaç ve pestisitler gibi günlük hayatta sıkça karşılaşılan maddeler de eklenince toksikolojik analizlerin zorluğu daha net anlaşılmaktadır (20). Hangi tür madde ile zehirlendiği bilinmeyen bir canlıdan alınan örnekte, taranması gereken madde sayısına ek olarak maddelerin kimyasal yapılarındaki farklılıklar analiz ve teşhisi etkileyen önemli unsurlardır. Polarapolar, asidik-bazik, uçuculuk gibi değişken kimyasal özellikler gösteren bileşiklerin örnek hazırlama ve analiz metotları birbirinden oldukça farklıdır. Bunun yanında toksik gazlar, uçucu bileşikler, metal iyonları, organik bileşikler, ilaç ve pestisitler gibi çok sayıda farklı madde, kan, idrar, dışkı, organ parçaları, saç-kı1 vb. karmaşık matriksler içerisinde çok düşük konsantrasyonlarda bulunabilmektedir (11). Ayrıca ölüm sonrası toplanan örneklerde çürümekokuşma oluşması dolayısıyla zehir tespiti zorlaşmaktadır (18). Belirtilen nedenlerle zehirlenen canlıdan alınan örneklerde, çok sayıda ve farklı fizikokimyasal özellikte maddenin konvansiyonel metotlarla incelenebilmesi mümkün değildir (34). Bu bağlamda sistematik toksikolojik analiz (STA) adı verilen genel tarama yöntemi, toksikoloji laboratuvarlarının doğru analiz ve teşhis çabası ile ilgili en önemli temeli oluşturmaktadır. STA, biyolojik örneklerde ilaç, pestisit, bitkisel/hayvansal zehir, kimyasal madde vb. çok çeşitli bileşiğin genel olarak taranması ve analiz edilmesine dair metot, bilgi ve birikimleri barındıran çok aşamalı bir süreci ifade etmektedir. STA süreci analizi yapılacak örneğin laboratuvara ulaştığı andan, analiz ve teşhis raporunun tamamlanmasına kadar olan süreyi kapsar. Laboratuvara ulaşan örnek, daha önce belirlenen STA protokolü ile uygun fraksiyonlara ayrılarak çeşitli örnek hazırlama yöntemlerinden geçirilir ve tüm fraksiyonlar test edilerek zehirli maddenin tespiti için gerekli işlemler gerçekleştirilir. STA'nın ilk aşamalarında tespit edilen maddeler (kalitatif analiz), sonraki aşamalarda miktarlarını tayin etmek (kantitatif analiz) ve değerlendirilmek üzere farklı metotlarla analiz edilir $(20,39)$. Bu analizleri kapsayan STA süreci genellikle birbirini takip eden basamaklardan oluşmaktadır. Veteriner hekimlikte STA süreci ile ilgili örnek basamaklar Şekil 1'de gösterilmiştir.

STA'nın esas amacı ve görevi, nedeni bilinmeyen zehirlenme vakalarında zehirlenmeye yol açan toksik bileşiği tanımlamaktadır (39). Laboratuvara ulaşan çeşitli örnekler, STA süreci ile öncelikle uygun fraksiyonlara ayrılırlar. Daha sonra immünolojik testler, fotometrik ya da genel kromatografik tarama ile negatif numuneler belirlenerek ayrılır; pozitif numuneler ise kütle spektrometresi gibi gelişmiş metotlarla kalitatif (nitel) ve kantitatif (nicel) olarak tespit edilirler $(18,19)$. Ölüm nedeni bilinmeyen, zehirlenme şüpheli vakalarda analitik bulgular büyük önem taşımaktadır. Bu bağlamda klinik bulgulardan yola çıkılarak yapılan analizler yardımıyla, klinik bulgu ya da şüphelenilen zehir olmaması durumunda ise STA prensiplerine uygun olarak yapılan analizler ile sonuca varılabilmektedir (37).

STA kapsamında önemli bir faktör de olayın gerçekleştiği çevredir. Zehirlenme olayının gerçekleştiği bölge gerek klinik yaklaşım gerekse toksikolojik incelemeler için ön fikir verebilmektedir. Tarımsal alanlarda herbisit ve diğer pestisit zehirlenmeleri $(13,28)$, sanayi bölgeleri ve fabrika çevrelerinde ağır metal zehirlenmesi $(6,14,42)$, nüfusun yoğun olarak yaşadığı bölgelerde ve çiftlik çevreleri gibi kırsal alanlarda rodentisit zehirlenmesi $(40,46)$ daha yüksek oranlarda görülmektedir. Ayrıca coğrafi bölgeye bağlı olmakla beraber zehirli bitki (zakkum, baldıran, kurtboğan) ve nadiren mantar zehirlenmesi görülebilmektedir (4, 43). Bu nedenlerle toksikoloji laboratuvarlarının hizmet verdiği bölgeleri tanıması ve zehirlenme nedenlerinin ortaya konulması daha hızlı ve doğru analiz için büyük fayda sağlamaktadır. Bölgede sık rastlanan zehirlenme vakalarının ve zehirli maddelerin tespiti aslında etkili bir STA 
protokolünün ilk basamağını oluşturmaktadır. Bu sayede taranacak toksik madde sayısı daraltılıp, doğru tespit oranı ve hızı artırılabilmektedir.

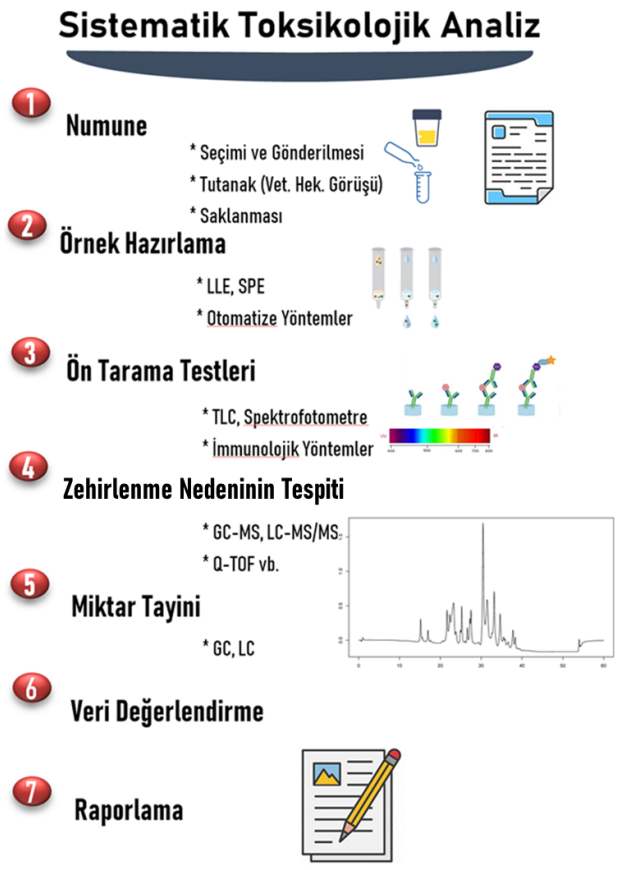

Şekil 1: Veteriner hekimlikte sistematik toksikolojik analiz basamakları

Figure 1: Systematic toxicological analysis steps in veterinary medicine

(LLE: Liquid-Liquid Extraction, Sivı-Slvı Ekstraksiyonu; SPE: Solid Phase Extraction, Katı Faz Ekstraksiyonu; TLC: Thin Layer Chromathography, Ince Tabaka Kromatografisi; GC-MS: Gaz Chromatography-Mass Spectrometry, Gaz Kromatografi-Kütle Spektrometresi; LC-MS/MS: Liquid Chromatography-Tandem Mass Spectrometry, Sivı Kromatografi-Siralı Kütle Spektrometresi; QTOF: Quadrupole Time of Flight Mass Spectrometry, Dört kutuplu Uçuş Zamanlı Kütle Spektrometresi; GC: Gaz Chromatography, Gaz Kromatografi; LC: Liquid Chromatography, Sivi Kromatografi).

$\mathrm{Bu}$ bilgiler 1şı̆̆ında bu çalışmada, STA prensipleri çerçevesinde ilk adım olacak şekilde Samsun ili ve çevresinde veteriner hekimlikte sıklıkla rastlanan zehirlenme nedenlerinin belirlenmesi amaçlandı. Bunun yanı sıra Samsun merkez ve ilçelerinde görev yapan veteriner hekimlerin zehirlenme vakalarına genel yaklaşımı, zehirlenme vakaları ve zehirlenmeye neden olan ajanlar ile ilgili tespitleri, örnek gönderme ve teşhis ile ilgili farkındalık düzeylerinin belirlenmesi hedeflendi.

\section{Gereç ve Yöntem}

$\mathrm{Bu}$ çalışmada etkin ve güvenilir bir STA protokolünün oluşturulması için ilk adım olan bölgedeki zehirlenme nedenlerinin ortaya konmasına dayanak olacak şekilde, Samsun ilinde çeşitli sektörlerde görev yapan 40 veteriner hekime anket uygulandı. Hazırlanan anket formunda veteriner hekimin cinsiyeti, çalıştığı kurum, görev yaptığı ilçe, mesleki tecrübesi, ağırlıklı olarak hekimlik uygulamalarını gerçekleştirdiği hayvan türü, son beş yılda rastladıkları zehirlenme şüpheli vaka sayısı, zehirlenen hayvan türleri, zehirlenmeye neden olan etkenler ve gözlenme sıklıkları, zehirlenme şüpheli numune alımı, belirtilenler dışında herhangi bir zehirlenmeye rastlayıp rastlamadıkları ve bu konuda eğitim almayı düşünüp düşünmedikleri ile ilgili toplam 11 adet soru yöneltildi. Anket formu yüz yüze veya çevrim içi (Google Docs) yolla katılımcılara uygulanarak elde edilen bulgular değerlendirildi. Çalışma dizaynı Ondokuz Mayıs Üniversitesi Sosyal ve Beşeri Bilimler Etik Kurulu tarafından onaylandı. 


\section{Bulgular}

Çalışmaya Samsun ilinde farklı ilçelerde görev yapan toplam 40 veteriner hekim (38 erkek, 2 kadın) katıldı. Katılımcıların 16'sının kamuda, 19'unun özel klinikte, 4'ünün hayvan hastanesinde, 1 katılımcının büyükbaş çiftliğinde, 1 katılımcının belediyede ve 1 katılımcının üniversitede görev yaptığı belirlendi. Katılımcıların ağırlıklı olarak çiftlik hayvanları ile çalıştıkları, bunu pet ve kanatlı hayvan hekimliğinin izlediği belirlendi. Katılımcılarının hekimlik uygulamalarını gerçekleştirdikleri hayvan türlerinin sayısal olarak dağılımları Tablo 1'de gösterilmiştir.

Tablo 1: Katılımcıların ağırlıklı olarak hekimlik uygulamalarını gerçekleştirdikleri hayvan türleri*

Table 1: Animal species in which the participants mainly perform their medical practices

\begin{tabular}{lc}
\hline Hayvan Türü & Katılımcı sayısı \\
\hline Çiftlik Hayvanları & 30 \\
Pet Hayvanları & 19 \\
Kanatlı Hayvanlar & 10 \\
Su Ürünleri & 4 \\
Egzotik Hayvanlar & 2 \\
At & 1 \\
Yaban Hayvanları & 1 \\
\hline
\end{tabular}

*Katllimcllar birden fazla hayvan türü belirtebilmişlerdir.

Katılımcıların son beş yıl içerisinde Samsun ilinde karşılaştıkları hayvan türlerine göre zehirlenme şüpheli vaka sayıları Tablo 2'de gösterilmiştir. Hayvan türleri arasında en fazla zehirlenmenin köpeklerde (131 zehirlenme vakası) olduğu görülürken, bunu sığır (109 vaka), koyun (76 vaka), kedi ve kanatlı hayvanlar (66'şar adet) izlemektedir. Bu periyot içerisinde Samsun ve çevresinde en az zehirlenme ise atlarda (2 vaka) rapor edilmiştir.

Tablo 2: Hayvan türlerine göre zehirlenme şüpheli vaka sayıları*

Table 2: Number of suspected cases of poisoning by animal species

\begin{tabular}{lc}
\hline Hayvan türü & Zehirlenme şüpheli vaka sayısı \\
\hline Köpek & 131 \\
Sığır & 109 \\
Koyun & 76 \\
Kedi & 66 \\
Kanatlı Hayvanlar & 66 \\
Keçi & 22 \\
Egzotik Hayvanlar & 22 \\
Manda & 13 \\
At & 2 \\
\hline
\end{tabular}

*Katıllmcılar birden fazla hayvan türü seçebilmişlerdir.

Zehirlenme vakalarında veteriner hekimler tarafindan anamnez, klinik bulgular ya da laboratuvar sonuçları esas alınarak belirlenen zehirleyici etkenler Şekil 2'de belirtilmiştir. Şekilde de görüldüğ̈ gibi en sık tespit edilen zehirlenme nedeni pestisitlerdir (antikoagülan ve diğer rodentisitler, organik fosforlu ve diğer insektisitler, herbisitler). Evcil hayvanlarda pestisitleri takiben en fazla zehirlenmeye neden olan etkenlerin ise bitkisel zehirler ve ilaçlar olduğu görülmektedir.

Katılımcıların zehirlenme şüpheli vakalarda laboratuvardan yardım alma durumlarına bakıldığında 26 katılımcı (\% 65) son 5 yıl içerisinde zehirlenme şüphesi ile kesin teşhis için laboratuvara örnek göndermediğini, 14 katılımcı (\% 35) ise örnek gönderdiğini belirtmiştir. Laboratuvara örnek gönderen katılımcıların büyük çoğunluğu $(\mathrm{n}=12)$ son 5 yıl içerisinde sadece 1-5 arasında, 1 katılımcı 6-10 arasında ve 1 katılımcı ise 20'den fazla örnek gönderdiğini belirtmiştir (Şekil 3). 


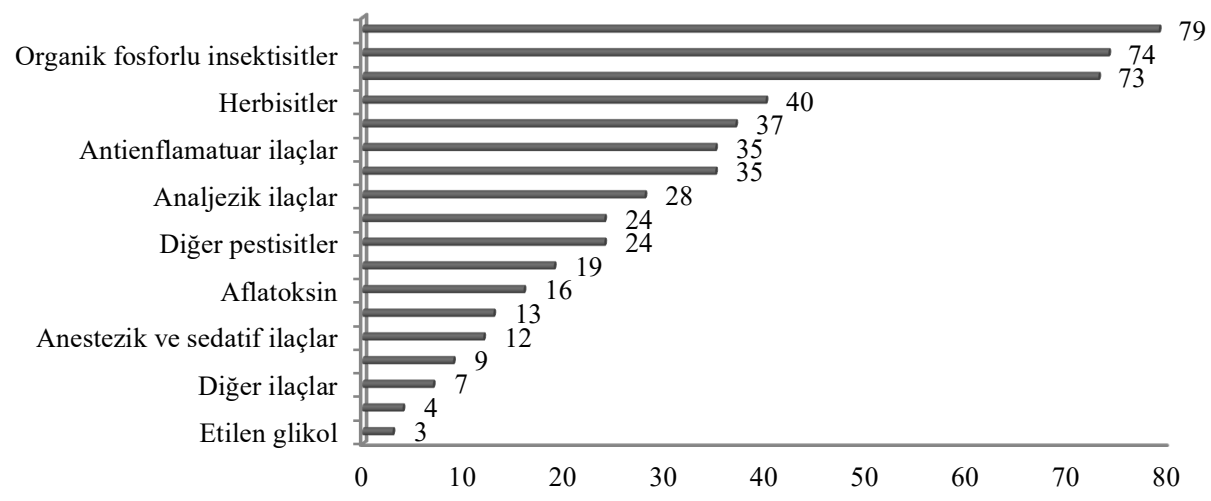

Şekil 2: Samsun bölgesinde son 5 y1lda zehirlenmeye neden olan etkenler (katılımcılar birden fazla zehirlenme etkeni seçebilmişlerdir).

Figure 2: Factors causing poisoning in the Samsun region in the last 5 years (participants could choose more than one poisoning agent).

Veteriner hekim tarafından konulan teşhis ile laboratuvar sonucu arasındaki uyuma bakıldığında 6 katılımcı kendi koydukları teşhislerin yarısından daha azının laboratuvar sonuçlarıyla uyumlu olduğunu belirtmiştir. Konulan teşhis ile laboratuvar sonucu arasındaki uyum oranının 5 katılımcı tarafından \%50-70, 3 katılımcı tarafından ise \%70'in üzerinde olduğu belirtilmiştir (Şekil 3).

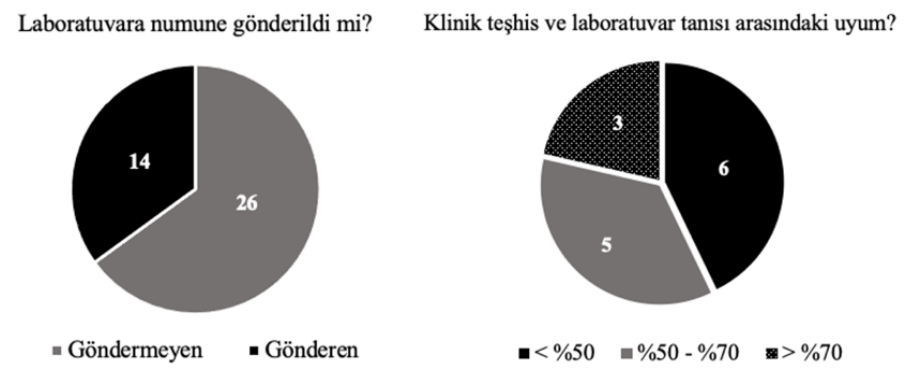

Şekil 3: Laboratuvara örnek gönderme oranları ve klinik ile laboratuvar arasındaki teşhis uyumu.

Figure 3: Sample sending rates to the laboratory and diagnostic compatibility between clinic and laboratory.

Laboratuvara örnek gönderen katılımcılar $(\mathrm{n}=14)$, en fazla tam kan ve serum gönderdiklerini, bunları takiben mide-rumen içeriği ve karaciğer örneği göndermeyi tercih ettiklerini belirtmişlerdir (Şekil 4).

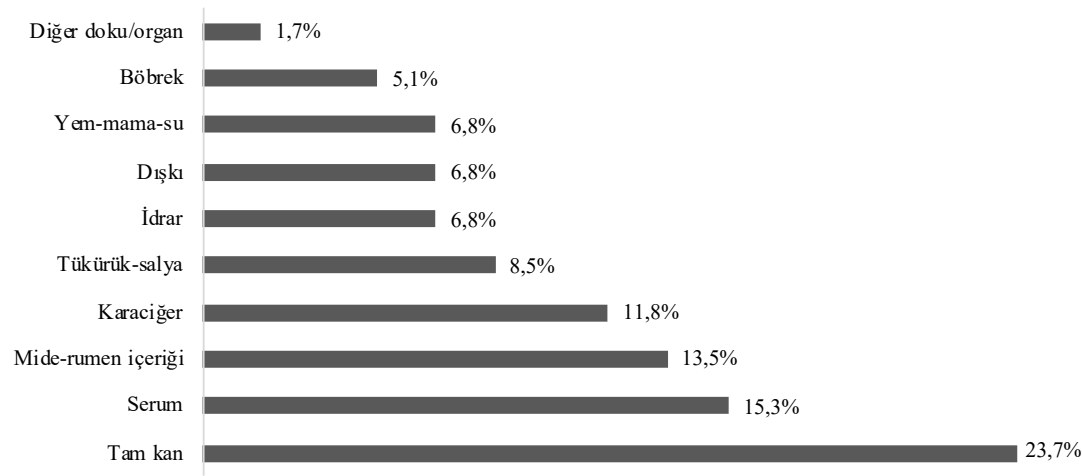

Şekil 4: Katılımcıların sıklıkla laboratuvara gönderdiği marazi madde türleri ve oranları.

Figure 4: Types and rates of morbid substances that participants frequently send to the laboratory 


\section{Tartışma ve Sonuç}

Zehirlenme nedeniyle meydana gelen ölümler, enfeksiyöz hastalıklar ya da travma gibi nedenlere bağlı ölümlerle karşılaştırıldığında daha az sayıda gerçekleşmektedir. Gözlenme sıklığının daha az olmasının yanı sıra, zehirleyici maddeler ve etkileri, bazı hayvan türlerinin belirli maddelere karşı duyarlılığı gibi konulardaki bilgi eksikliği veteriner hekimlerin ve hayvan sahiplerinin zehirlenme vakalarına yaklaşımını olumsuz yönde etkilemektedir (21). Ayrıca tanı konulamayan ya da önemsenmeyen birçok vaka gerçek zehirlenme sayısı hakkında yanıltıcı olurken, besin değeri olan kasaplık hayvanların zehirlenme nedeniyle bilinçsizce kesime sevk edilmesi tüketici açısından risk teşkil etmektedir. Bu çalışmada, katılımcıların tamamı zehirlenme şüpheli vakalar ile karşılaşmış ancak sadece \% 35'i (n=14) çoğunlukla birkaç vaka ile sınırlı olmak üzere kesin teşhis için laboratuvara örnek göndermiştir. Zehirlenme vakalarında hayvan öldürücü doza maruz kalmış ise klinik bulgulardan yola çıkılarak yapılan semptomatik tedavi genellikle hayat kurtarmak için yeterli olmamaktadır. Bu nedenle laboratuvar bulguları ve klinik bulgular birleştirilerek yapılacak teşhisler, özellikle kazara ya da kasti olarak gerçekleşen toplu zehirlenmelerde hayat kurtarıcı olabilmektedir (10).

Hayvanlarda zehirlenmeye neden olan etkenler arasında pestisitler ilk sırada gelmektedir. Birçok retrospektif çalışmada, pestisitler nedeniyle gerçekleşen ölümlerin, diğer tüm zehirleyici ajanların neden olduğu ölümlerden daha fazla sayıda olduğu belirtilmektedir $(13,35)$. Benzer şekilde bu çalışmada da katılımcılar karşılaştıkları zehirlenme şüpheli vakaların \% 43'ünü pestisitlerin (herbisit, insektisit ve rodentisit) oluşturduğunu belirtmişlerdir. Pestisitler içerisinde ise öncelikle rodentisitler en sık zehirlenme nedeni olarak ortaya çıkarken, insektisit ve herbisitlerin bunu takip ettiği görülmektedir. Yapılan diğer çalışmalarda da insektisit ve rodentisitler özellikle pet hayvanlarında en sık zehirlenme sebebi olarak gösterilmektedir (6). Amerika Birleşik Devletleri ve Kanada'da 2002-2017 yıllarını kapsayan 16 yıllık dönemde, pet hayvanlarında zehirlenme şüpheli vakalarda zehirleyici madde olarak en sık insektisit, rodentisit, ilaç, bitki, evde kullanılan temizlik malzemeleri ve çikolata belirtilmiştir $(31,32)$. İtalya'da benzer şekilde pestisitler birincil zehirlenme sebebi olarak tespit edilmiş, pestisitler içerisinde ise sırasılya insektisit, rodentisit, molluskusit ve herbisitler en sık zehirlenmeye yol açan bileşikler olarak belirlenmiştir. Benzer şekilde Wang ve ark. (49) toksikolojik analiz için laboratuvarlarına gönderilen zehirlenme şüpheli karaciğer ve mide içeriği örnekleri ve ayrıca tuzak yem şüpheli toplam 300 adet numuneyi analiz ederek, 175 numunede pestisit saptamış, bunların \% 50'ye yakının karbamatlı insektisit içerdiğini belirtmiştir. Ayrıca zehirleyici maddeler sıklık açısından sırasıyla antikoagülan rodentisitler, organik fosforlu insektisitler, antikoagülan olmayan rodentisitler, molluskusit ve herbisitler, diğer zehirleyici bileşikler olarak tespit edilmiştir. Ölümle sonuçlanan pestisit zehirlenme vakalarında, karbamatlı pestisitlerin öne çıtı̆̆g, bunun yanı sıra organik fosforlu pestisitler, rodentisitler, mikotoksinler gibi zehirleyici ajanların da sıkça ölüme sebep olduğu belirtilmektedir $(29,41)$. Allkämper ve ark. (2) tarafından yapılan bir diğer çalışmada, retrospektif olarak kedi ve köpeklerde zehirlenme nedenleri araştırılmış, benzer şekilde rodentisit grubu içerisinde yer alan kumarin türevlerinin (dikumarol, warfarin vb.) \% 37'lik oran ile ilk sırada, ilaçların \% 10 ile ikinci sırada, çikolata zehirlenmesinin ise $\% 7$ ile üçüncü sırada olduğu tespit edilmiştir. Irak ve Yılmaz (25) tarafından 2000-2004 yılları arasında ülkemizde 4 farklı ilde (Ankara, Van, Elâzığ, Konya) hayvanlarda gerçekleşen zehirlenme olgularının değerlendirildiği retrospektif çalışmada çeşitli hayvan türlerinde toplam 470 zehirlenme olgusu tespit edilmiştir. Bu çalışmada ise en sık rastlanan zehirleyici maddelerin başta pestisitler olmak üzere, çikolata, aflatoksinler, aspirin ve ektoparaziter ilaçlar olduğu ortaya konmuştur.

Yukarıda belirtildiği gibi kemirgen mücadelesinde kullanılan rodentisitler pet hayvanları ve yaban hayvanlarında sıç̧a zehirlenmeye sebep olan bileşiklerdendir (47). Piyasada bulunan rodentisitlerin \% 90'dan fazlası antikoagülan özelliktedir ve tuzak yem olarak kullanılan bu maddeler, hedef dışı canlılar tarafından tüketilerek ya da sekonder maruziyet nedeniyle zehirlenmelere yol açabilmektedir $(30,35,44)$. Bu çalışmada zehirlenme şüpheli 79 vakanın antikoagülan, 13 vakanın ise diğer tipte rodentisit maruziyeti sonucu meydana geldiğinin belirtilmesi, antikoagülan rodentisitlerin ülkemizde de hayvanlarda zehirlenmeler açısından ciddi bir risk teşkil ettiğini göstermektedir.

Zehirlenme sebepleri arasında ilk sıralarda gelen bir başka madde grubu ise ilaçlardır. Doz aşımı, tür duyarlılığı ya da etiket dışı ilaç kullanımı neticesinde başta pet hayvanları olmak üzere birçok hayvan zehirlenebilmektedir. Hayvanlarda sıkça zehirlenmeye yol açan ilaçlar arasında sırasıyla analjezikler (non-steroid antiinflamatuvar ilaçlar), antihistaminikler, kardiyovasküler ilaçlar, merkezi sinir sistemi ilaçları bulunmaktadır (15). Bu çalışmada veteriner 
hekimler tarafından belirtilen zehirlenme şüpheli vakaların \% 27'si ilaçlar nedeniyle meydana gelmiş ve ilaçlar içerisinde olgu bakımından sırasıyla antiparaziter, analjezik ve antiinflamatuvar ilaçlara bağlı zehirlenmeler bildirilmiştir.

Akrep, yılan gibi zehirli hayvanların sokması sonucu hayvanlarda gerçekleşen zehirlenmeler ülkemizde genellikle göz ardı edilmektedir. Bu çalışmada 37 (\% 6.9) vaka ile zehirli hayvan sokması, zehirlenme sebepleri arasında 5. sırada yer almıştır. Bu oran diğer ülkelerle karşılaştırıldığında nispeten düşüktür. Örneğin, zehirli hayvan popülasyonu yönünden oldukça zengin olan Avustralya'da yıllık ortalama 6200 vaka bildirilirken, çiftlik hayvanlarının yanı sıra kedi ve köpeklerin en çok etkilenen hayvanlar oldukları ve vakaların büyük oranda kırsal bölgelerde meydana geldiği rapor edilmektedir $(9,33)$.

Bitkisel zehirlenmeler ile genellikle çiftlik hayvanlarında ve özellikle ruminantlarda daha sik karşılaşılmaktadır. Merada otlayan hayvanlar bölgedeki zehirli bitkileri tanıyarak tüketmemekte ancak hayvanların çok aç olması, kuraklık, aşırı otlatma, merada zehirli bitki popülasyonu artışı gibi nedenler bitkisel zehirlenme insidansını artırabilmektedir (17). Ülkemiz ve Samsun ili meralarında birçok zehirli bitki türü mevcuttur $(4,45)$. Bu bağlamda son beş yılda bitkisel zehirlenme şüpheli olarak bildirilen 73 vaka (\%13.7), Samsun bölgesinde bitkisel zehirlenmelerle sıkça karşılaşıldığını göstermektedir.

Tür bazında zehirlenme şüpheli vaka sayısı çoktan aza doğru köpek, sığır, koyun, kanatlı hayvanlar, kedi, egzotik hayvanlar, keçi, manda ve at sırasıyla tespit edilmiştir. Dünya genelinde yapılan retrospektif çalışmalarda da hayvan zehirlenmelerine en sık maruz kalan tür köpekler olarak ortaya çıkmaktadır $(2,6,13,15,29)$. Amerika Birleşik Devletleri ve Kanada'da 2002-2010 yılları arasında tespit edilen zehirlenme şüpheli vakalarının \% 76'sı köpeklerde, \% 13’ü kedilerde gerçekleşmiştir (31). Kanada'da 2011-2017 yılları arasında zehirlenme şüpheli vakaların \% 63'ünün köpeklerde, \% 6'sının ise kedilerde görüldüğü rapor edilmiştir (32). İsviçre'de 10 yıllık periyotta yapılan incelemede 1546 hayvan zehirlenme vakası tespit edilmiş; köpeklerde 865 (\% 57), kedilerde 391 (\% 25) vaka bildirilirken, çiftlik hayvanlarında (koyun, keçi ve sığır) toplamda 150 vaka (\% 17) tespit edilmiştir (16). Fransa'da hayvanlarda antikoagülan rodentisit zehirlenmelerinin araştırıldığı bir çalışmada vakaların \% 75'inin köpeklerde, \% 9'unun ise kedilerde (7); Avusturya'da hayvanlarda pestisit zehirlenmelerinin araştırıldığı çalışmada vakaların \% 47'sinin köpeklerde ve \% 34'ünün kedilerde meydana geldiği bildirilmiştir (49).

$\mathrm{Bu}$ çalışmada, veteriner hekimlik uygulamalarını çiftlik hayvanları üzerinde gerçekleştiren katılımcı oranı \% $45(n=18)$, pet hayvanları üzerinde gerçekleştiren katılımcı oranı ise \% $28(n=11)$ 'dir. Diğer çalışmalarda tespit edilen zehirlenme vakalarının görüldüğü hayvan türleri arasında genellikle ilk sıraları kedi, köpek gibi pet hayvanları alırken bu çalışmada köpeklerden sonra en sık zehirlenme vakalarının çiftlik hayvanlarında olduğu belirlenmiştir. Bu bağlamda katılımcıların mesleki uygulamalarının daha çok çiftlik hayvanları ile ilgili olması çiftlik hayvanlarında vaka sayılarının öne geçmesine neden olmuştur. Çiftlik hayvanlarının otobur hayvanlar olması dolayısıyla bitkisel zehirlenmeler açısından riskli grupta yer almaları doğaldır $(21,38)$. Benzer şekilde bu çalışmada bitkisel zehirlenme şüpheli vaka sayısının \% 13 ile 3. sırada gerçekleşmesinin, katılımcıların yüksek oranda ruminantlar üzerinde çalışması ve bu doğrultuda vaka bildiriminin yüksek olmasından kaynaklandığı düşünülmektedir.

Atlarda zehirlenme vakaları pet hayvanları ve çiftlik hayvanlarına kıyasla çok daha az sayıda ortaya çıkmaktadır. Atlarda genellikle herbisit ve rodentisit zehirlenmeleri bildirilmekte, ruminantların yanı sıra atlarda da bitkisel zehirlenmeler gözlenmektedir $(5,12)$. Bu çalışmada da atlarda zehirlenme vakaları diğer türlere göre çok daha az rapor edilmiştir. Ancak bunun bir nedeninin de atların çalışmaya katılan veteriner hekimlerin çalışma alanı dışında olduğu unutulmamalıdır.

Zehirlenme vakalarında bir diğer önemli unsur ise ülkemizde de sıç̧a meydana gelen kasti amaçlı zehirlemelerdir. Kasti olarak yapılan zehirlemelerde kolaylıkla elde edilebilen rodentisit, insektisit, herbisit ya da nadiren striknin karıştırılmış tavuk eti, kıyma gibi maddelerle, çoğunlukla kedi ve köpekler zehirlenmektedir (23). Konu ile ilgili yapılan literatür taramasında ülkemizde yapılan tek bir çalışmaya rastlanmış ve 30 adet köpeğin kasıtlı olarak methomil (karbamatlı pestisit) ile zehirlendiği bildirilmiştir (36).

Ülkemizde, yaygın olarak görülen zehirlenme nedenlerinin yanı sıra çeşitli maddelerin sebep olduğu nadir vakalar da rapor edilmiştir. Bir kedide ve köpekte molluskusit (metaldehit) zehirlenmesi (1,50); bir atta levamizol zehirlenmesi (27); bir köpekte sipermetrin (26) ve amitraz zehirlenmesi (3), bir muhabbet kuşunda çikolata 
zehirlenmesi (48) gibi farklı hayvan türlerinde ve nadir rastlanan maddelerle zehirlenmeler bildirilmiştir. Bu çalışmada katılımcı veteriner hekimler, Samsun bölgesinde anket formunda belirtilen seçenekler dışında nitrit-nitrat, boya, sodyum hipoklorit ve çeşitli temizlik malzemeleri ile ilgili zehirlenmelerle karşılaştıklarını belirtmişlerdir.

Zehirlenme şüpheli vakalarda laboratuvar analizleri ile ilgili olarak veteriner hekimlerin laboratuvara çoğunlukla örnek göndermediği ve gönderilen örneklerde laboratuvar bulguları ile anamnez-klinik teşhisin genellikle uyum sağlamadığı tespit edilmiştir. Bu durum zehirlenme şüpheli bazı vakalarda, titreme, kusma, defekasyon, çırpınma, solunum güçlüğü gibi genel zehirlenme semptomlarının birbiri ile ve diğer hastalıklarla karışarak klinik teşhisi güçleştirdiğini göstermektedir. Veteriner hekimler özellikle anamnez ile alınan bilgilerin yeterli ya da şüpheli olduğu durumlarda, sıklıkla zehirlenme belirtilerine yönelik genel tedavi seçeneklerini tercih etmek durumunda kalmakta ve tedavi zaman zaman başarısız olmaktadır. $\mathrm{Bu}$ nedenle bölgesel ölçekte toksikolojik analiz yapan laboratuvarlara ve veteriner hekimlerin bu laboratuvarlara yönlendirilmesine ihtiyaç duyulmaktadır.

$\mathrm{Bu}$ durum STA prensibi ile zehirlenme vakalarına yaklaşılmasının önemini ortaya koymaktadır. STA prensipleri ile değerlendirilen numunelerde kesin teşhis hızlı ve doğru biçimde konulabilmekte, bu durum akut vakalarda doğru müdahale şansını artırırken, adli vakalarda verilecek karara önemli ölçüde yardımcı olmaktadır. Bu bağlamda toksikoloji laboratuvarlarının, hizmet verdiği bölgede sık karşılaşılan zehirlenme nedenlerini tespit ederek çalışma basamaklarını bu tespitlere göre düzenlemesinin önemi tekrar ortaya çıkmaktadır.

İnsektisit, rodentisit, herbisit gibi pestisitlerin yanı sıra ilaçlar, fitotoksinler, aflatoksinler gibi çok sayıda zehirleyici maddenin tespiti için standart analiz metotları hem çok zaman alıcı hem de yüksek maliyetlidir. Ayrıca analiz laboratuvarları tarafindan elde edilen bulguların, tedaviyi yönlendirmesi, idari ya da kanuni sonuçlar doğurabilmesi bakımından mümkün olduğunca hatasız ve kesin olması gerekmektedir (19). Bunun yanında toksikoloji laboratuvarlarında binlerce maddeyi aynı anda tespit edebilecek tek bir analiz yöntemi bulunmamaktadır. Şüphelenilen zehirler fizikokimyasal özelliklerine göre gruplandırılarak tek tek test edilmekte, her bir test için zehirlenme şüpheli numunenin bir kısmı kaybedilmekte ve her bir test için ayrı maliyet meydana gelmektedir. Bu nedenle plansız ve programsız olarak rastgele gerçekleştirilen testler teşhis şansını ciddi biçimde düşürerek ekonomik olmaktan uzaklaşmaktadır (23).

Ülkemizde hayvanlarda zehirlenmeye neden olan kimyasal maddeleri tanımlayan ve bunları raporlayan nitelikli laboratuvar sayısı son derece azdır. Zehirlenme olgularının, ülkeler bazında ve bölgesel düzeyde belirlenmesi, istatistiksel verilerin ortaya konulması, tanı ve tedavi seçeneklerinin oluşturulması son derece önemlidir. Belirtilen nedenlerle toksikoloji laboratuvarlarının konvansiyonel yöntemlerden ziyade bilgi, birikim ve metot kapasitelerini tamamlayarak STA prensipleri ile çalışması kaçınılmazdır. STA protokolünün geliştirilmesi; zehirlenme nedenlerinin yüksek doğrulukta belirlenmesi, laboratuvar ve personel alt yapısının konuyla ilgili nitelik kazanması ve elde edilen verilerin ortaya konulmasını sağlayacaktır. Bu protokolde görev alacak veteriner hekim ve diğer personele, konuyla ilgili verilecek bilgi ve eğitimler ile sürecin en doğru şekilde işlemesi sağlanacaktır. Böylece, STA ile zehirlenme vakalarına yaklaşım ve gelecekte olası zehirlenme vakalarının önlenmesi adına yapılacak çalışmalar bilimsel tabanda sürdürülebilecektir. Bu çalışmada STA protokolünün ilk adımı olan bölgemizdeki zehirlenme nedenlerinin ortaya konmasına yardımcı olması amacıyla veteriner hekimlerin karşılaştıkları zehirlenme vakaları değerlendirilmiştir. Ülkemizde etkili ve güvenli toksikolojik analiz laboratuvarlarının geliştirilmesine dayanak oluşturacak şekilde daha fazla denek sayısı ile Türkiye geneline yayılmış daha geniş çaplı ileri çalışmaların yapılması son derece yararlı olacaktır.

\section{Çıkar Çatışması Beyanı}

Yazarların çalışma kapsamında herhangi bir kişisel ve finansal çıkar çatışması bulunmamaktadır.

\section{Finansal Kaynak Beyanı}

Bu çalışma Ondokuz Mayıs Üniversitesi tarafından PYO.VET.1901.19.001 proje numarası ile desteklenmiştir.

\section{Yazar Katkısı Beyanı}

Fikir/kavram: Oğuzhan YAVUZ Deney tasarımı: Oğuzhan YAVUZ, Orhan TOKUR, Özge MARANGOZ, Zeyno NUHOĞLU, Saima MUSHTAQ Denetleme/Danışmanlık: Oğuzhan YAVUZ Veri toplama: Orhan TOKUR, Özge MARANGOZ, Zeyno NUHOĞLU, Saima MUSHTAQ, Aylin PEHLIVAN, Oğuzhan YAVUZ Veri analizi ve yorum: Oğuzhan YAVUZ, Orhan TOKUR Kaynak taraması: Orhan TOKUR, Özge MARANGOZ, Zeyno NUHOĞLU, Saima 
MUSHTAQ, Aylin PEHLIVAN, Oğuzhan YAVUZ Makalenin yazımı: Orhan TOKUR, Özge MARANGOZ, Zeyno NUHOĞLU, Saima MUSHTAQ, Aylin PEHLIVAN, Oğuzhan YAVUZ Eleştirel inceleme: Oğuzhan YAVUZ Etik Onay

Bu çalışma Ondokuz Mayıs Üniversitesi Sosyal ve Beşeri Bilimler Etik Kurulu tarafindan 25.12.2020 tarih ve 2020/915 sayı ile onaylanmıştır.

\section{Kaynaklar}

1. Alihosseini H, Özkaptan İ, Dedecanoğlu E (2015): Golden retriever ırkı bir köpekte metaldehyde toksikasyonun (salyangoz ilacı zehirlenmesi) başarılı tedavisi ve yönetimi. 1. Küçük Hayvan Veteriner Hekimleri Derneği Sürekli Eğitim Kongresi. İstanbul.

2. Allkämper S, Kösters S, Campe A, Kietzmann M, Kreienbrock L (2018): Cases of suspected poisoning in small animal practice-a retrospective and prospective survey. Tierarztl Prax, 46(3), 145-155.

3. Aytekin İ, Altuğ N, Öztürk HO (2011): Bir köpekte amitraz toksikasyonu. Atatürk Üniversitesi Vet Bil Derg, 6(2).

4. Balabanlı C, Albayrak S, Türk M, Yüksel O (2006): Türkiye çayır-meralarında bulunan bazı zararlı bitkiler ve hayvanlar üzerindeki etkileri. Turk J For, 7(2), 89-96.

5. Bates N (2017): Acute poisoning in horses: part 1. Livestock, 22(2), 105-109.

6. Berny P, Caloni F, Croubels S, Sachana M, Vandenbroucke V, Davanzo F, Guitart R (2010): Animal poisoning in Europe. Part 2: companion animals. Vet J, 183(3), 255-259.

7. Berny P, Velardo J, Pulce C, D'amico A, Kammerer M, Lasseur R (2010): Prevalence of anticoagulant rodenticide poisoning in humans and animals in France and substances involved. J Clin Toxicol, 48(9), 935-941.

8. Bertero A, Chiari M, Vitale N, Zanoni M, Faggionato E, Biancardi A, Caloni F (2020): Types of pesticides involved in domestic and wild animal poisoning in Italy. Sci Total Environ, 707, 136129.

9. Bolon I, Finat M, Herrera M, Nickerson A, Grace D, Schütte S, Martins SB, de Castañeda RR (2019): Snakebite in domestic animals: First global scoping review. Prev Vet Med, 170, 104729.

10. Boyle JS, Bechtel LK, Holstege CP (2009): Management of the critically poisoned patient. Scand J Trauma Resusc Emerg Vet, 17(1), 1-11.

11. Broecker S, Herre S, Wüst B, Zweigenbaum J, Pragst F (2011): Development and practical application of a library of CID accurate mass spectra of more than 2,500 toxic compounds for systematic toxicological analysis by LCQTOF-MS with data-dependent acquisition. Anal Bioanal Chem, 400(1), 101-117.

12. Caloni F, Cortinovis C, Rivolta M, Davanzo F (2012): Animal poisoning in Italy: 10 years of epidemiological data from the Poison Control Centre of Milan. Vet Rec, 170(16), 415-415.

13. Caloni F, Cortinovis C, Rivolta M, Davanzo F (2016): Suspected poisoning of domestic animals by pesticides. Sci Total Environ, 539, 331-336.

14. Choubisa SL, Choubisa D (2016): Status of industrial fluoride pollution and its diverse adverse health effects in man and domestic animals in India. Environ Sci Pollut Res, 23(8), 7244-7254.

15. Cortinovis C, Pizzo F, Caloni F (2015): Poisoning of dogs and cats by drugs intended for human use. Vet J, 203(1), 52-58.

16. Curti R, Kupper J, Kupferschmidt H, Naegeli H (2009): A retrospective study of animal poisoning reports to the Swiss Toxicological Information Centre (1997-2006). Schweiz Arch, 151(6), 265-273.

17. Demir AÖ, Kor D, Çelen AE (2010): Türkiye'de mera koşullarında beslenen küçükbaş hayvanların karşılaşması olası bazı zehirli bitkilerin ve zehirlenme belirtileri. YYU Fen Bilimleri Enstitüsü Dergisi, 15(1), 54-58.

18. Drummer OH, Gerostamoulos J (2002): Postmortem drug analysis: analytical and toxicological aspects. Ther Drug Monit, 24(2), 199-209.

19. Ferrara DS, Tedeschi L, Frison G, Brusini G (1998): Quality control in toxicological analysis. J Chromatogr B, 713(1), 227-243.

20. Gergov M, Boucher B, Ojanperä I, Vuori E (2001): Toxicological screening of urine for drugs by liquid chromatography/time - of - flight mass spectrometry with automated target library search based on elemental formulas. Rapid Commun Mass Spectrom, 15(8), 521-526.

21. Guitart R, Croubels S, Caloni F, Sachana M, Davanzo F, Vandenbroucke V, Berny P (2010): Animal poisoning in Europe. Part 1: Farm livestock and poultry. Vet J, 183(3), 249-254.

22. Guitart R, Sachana M, Caloni F, Croubels S, Vandenbroucke V, Berny P (2010): Animal poisoning in Europe. Part 3: wildlife. Vet J, 183(3), 260-265. 
23. Gwaltney-Brant SM (2016): Veterinary forensic toxicology. Vet Pathol, 53(5), 1067-1077.

24. Gwaltney - Brant SM (2007): Epidemiology of animal poisonings. 67-73. In: R. Gupta (Ed), Veterinary Toxicology: Basic and Clinical Principles. Academic Press, USA.

25. Irak K, Yılmaz O (2014): A retrospective evaluation of intoxication cases in animals of four different provinces between the years 2000 and 2004. YYU Vet Fak Derg, 25(2), 27-30.

26. İssi M, Baykalır BG, Gül Y (2014): Bir köpekte saptanan akut sipermetrin intoksikasyonu. YYU Vet Fak Derg, 25(1), 19-21.

27. İssi M, Gül Y, Başbuğ O (2010): Bir atta akut levamizol zehirlenmesi. Firat Üniversitesi Sağlık Bliimleri Veteriner Dergisi, 24(1), 47-50.

28. Kofod DH, Jørs E, Varma A, Bhatta S, Thomsen JF (2016): The use of self-reported symptoms as a proxy for acute organophosphate poisoning after exposure to chlorpyrifos $50 \%$ plus cypermethrin $5 \%$ among Nepali farmers: a randomized, double-blind, placebo-controlled, crossover study. Environ Health, 15(1), 122.

29. Lahmar R, Berny P, Mahjoub T, Youssef SB (2019): Animal pesticide poisoning in Tunisia. Front Vet Sci, 6. 30. López-Perea JJ, Mateo R (2018): Secondary exposure to anticoagulant rodenticides and effects on predators. 159-193. In: Anticoagulant rodenticides and wildlife. Springer, USA.

31. McLean MK, Hansen SR (2012): An overview of trends in animal poisoning cases in the United States: 20022010. Veterinary Clinics: Small Animal Practice, 42(2), 219-228.

32. Means C, Wismer T (2018): An overview of trends in animal poisoning cases in the United States: 2011 to 2017. Veterinary Clinics: Small Animal Practice, 48(6), 899-907.

33. Mirtschin P, Masci P, Paton D, Kuchel T (1998): Snake bites recorded by veterinary practices in Australia. Aust Vet J, 76(3), 195-198.

34. Moffat AC, Osselton MD, Widdop B, Watts J (2011): Clarke's analysis of drugs and poisons. Pharmaceutical press, London.

35. Murphy MJ, Talcott PA (2013): Anticoagulant Rodenticides. 435-445. In, Peterson ME, Tallcot PA (Eds), Small Animal Toxicology. Saunders, USA.

36. Özdemir Ö, Ateş MB, Ortatatli M, Terzi F, Tülay A, Hatipoglu F, Ciftci MK (2019): Dog massacre with pesticide for theft: methomyl poisoning. Kafkas Univ Vet Fak Derg, 25(5).

37. Peters FT, Steuer AE (2019): Antemortem and postmortem influences on drug concentrations and metabolite patterns in postmortem specimens. WIREs: Forensic Sci, 1(1), e1297.

38. Pfister JA, Provenza FD, Panter KE, Stegelmeier BL, Launchbaugh KL (2002): Risk management to reduce livestock losses from toxic plants. J Range Manag, 55(3), 291-300.

39. Samanidou V, Kovatsi L, Fragou D, Rentifis K (2011): Novel strategies for sample preparation in forensic toxicology. Bioanalysis, 3(17), 2019-2046.

40. Sánchez-Barbudo IS, Camarero PR, Mateo R (2012): Primary and secondary poisoning by anticoagulant rodenticides of non-target animals in Spain. Sci Total Environ, 420, 280-288.

41. Sell B, Sniegocki T, Zmudzki J, Posyniak A (2018): Development of an analytical procedure for the determination of multiclass compounds for forensic veterinary toxicology. J Anal Toxicol, 42(3), 183-191.

42. Sharaf S, Khan MUR, Aslam A, Rabbani M (2020): Comparative study of heavy metals residues and histopathological alterations in large ruminants from selected areas around industrial waste drain. Pak Vet J, 40(1).

43. Tokarnia CH, Döbereiner J, Peixoto PV (2002): Poisonous plants affecting livestock in Brazil. Toxicon, 40(12), 1635-1660.

44. Tokur O, Aksoy A (2018): Hayvanlarda rodentisitler nedeniyle oluşan ikincil zehirlenmeler. IV. Ulusal Vektör Mücadelesi Sempozyumu. Antalya.

45. Töngel MÖ, Ayan İ (2005): Samsun ili çayır ve meralarında yetişen bazı zararlı bitkiler ve hayvanlar üzerindeki etkileri. Anadolu Tarım Bilim Derg, 20(1), 84-93.

46. Valchev I, Binev R, Yordanova V, Nikolov Y (2008): Anticoagulant rodenticide intoxication in animals-a review. Turk J Vet Anim Sci, 32(4), 237-243.

47. Van den Brink NW, Elliott JE, Shore RF, Rattner BA (2018): Anticoagulant rodenticides and wildlife. Springer 48. Varol K, Ekinci G, Güneş V, Keleş İ, Onmaz AC (2019): Chocolate intoxication in a budgerigar. Erciyes Üniv Vet Fak Derg, 16(1), 73-76.

49. Wang Y, Kruzik P, Helsberg A, Helsberg I, Rausch W-D (2007): Pesticide poisoning in domestic animals and livestock in Austria: a 6 years retrospective study. Forensic Sci Int, 169(2-3), 157-160.

50. Yipel FA, Yipel M, Acar A (2013): Bir kedide sümüklü böcek ilacı (metaldehit) zehirlenmesi. Kocatepe Vet J, 6(2), $71-74$. 